\title{
Involuntary admission and hospitalization - clinical data in West Germany
} Dirk Richter* and Thomas Reker

Address: Westphalian Hospital Muenster, PO Box 202 252, Muenster, D-48103, Germany

* Corresponding author

from WPA Thematic Conference. Coercive Treatment in Psychiatry: A Comprehensive Review

Dresden, Germany. 6-8 June 2007

Published: 19 December 2007

BMC Psychiatry 2007, 7(SuppI I):S24 doi:10.1 I86/I47I-244X-7-SI-S24

This abstract is available from: http://www.biomedcentral.com/I47I-244X/7/SI/S24

(C) 2007 Richter and Reker; licensee BioMed Central Ltd.

The figures and rates of involuntary admissions to psychiatric hospitals have been considerably under discussion in recent years in German psychiatry. In the first part, this presentation reviews the relevant publications, the metholodological problems related to the topic and draws conclusions on several issues, e.g. the admission procedures in the community sector of West German mental health care. The second part presents data from the local public psychiatric hospital in Muenster, Germany, which cover more than 20 years of data collecting on involuntary admissions. These data offer a unique perspective on the clinical correlates of the involuntary admission procedures in West Germany. 